\title{
manejo Químico de Plantas Daninhas na Cultura do Milho em FunÇão de CaRACTERÍsticas Morfofisiológicas e REduÇão de EspaÇamento da Cultura ${ }^{1}$
}

\author{
Chemical Management of Weeds in Corn in Function of the Morphophysiological Characteristics \\ and Reduced Spacing
}
TREZZI, M.M. ${ }^{2}$, VIDAL, R.A. ${ }^{3}$, KRUSE, N.D. ${ }^{4}$, PRATES, M.V.B. ${ }^{5}$, GUSTMAN, M.S. ${ }^{6}$, NUNES, A.L. ${ }^{7}$ e ARGENTA, G. ${ }^{8}$

\begin{abstract}
RESUMO - Objetivou-se com este trabalho avaliar o efeito da integração de redução de espaçamento entre linhas sobre características morfofisiológicas de híbridos e estratégias de manejo químico de plantas daninhas em milho. O experimento foi realizado a campo, em delineamento de blocos casualizados, com quatro repetições, em um fatorial $2 \times 2 \times 5$, em que o primeiro fator representou os híbridos de milho (Sprint, ciclo superprecoce e folhas mais eretas, e Penta, ciclo precoce e folhas mais planas); o segundo, espaçamentos entre linhas de milho $(0,45$ e $0,90 \mathrm{~m})$; e o terceiro, tratamentos para controle de plantas daninhas: 1. atrazine + simazine $\left(1.500+1.500 \mathrm{~g}\right.$ i.a. ha $\left.{ }^{-1}\right)$ em pós-precoce; 2 . atrazine + simazine $\left(1.500+1.500\right.$ g i.a. ha $\left.{ }^{-1}\right)$, em pós-precoce, complementada por nicosulfuron + atrazine $(20+750$ g i.a. ha-1 $)$, em pós-tardia; 3. atrazine + simazine $(750+750$ g i.a. ha-1), em pósprecoce; 4. testemunha capinada; e 5. apenas nicosulfuron+atrazine $(20+750$ g i.a. ha-1), em pós -ardia. O espaçamento de $45 \mathrm{~cm}$ favoreceu a infestação de plantas daninhas na linha do milho, enquanto no espaçamento de $90 \mathrm{~cm}$ as maiores infestações foram observadas nas entrelinhas da cultura. As aplicações complementares de atrazine+nicosulfuron em pós-tardia foram importantes para controlar plantas daninhas no híbrido Sprint em espaçamento convencional, mas não necessárias para o híbrido Penta, nos espaçamentos utilizados. Observou-se no híbrido Penta que a redução do espaçamento afetou o rendimento de grãos, enquanto para Sprint não foi verificada redução de produtividade.
\end{abstract}

Palavras-chave: arranjo de plantas, controle cultural, manejo integrado de plantas daninhas.

\begin{abstract}
This work was carried out to evaluate the effect of integrating morphophysiological characteristics of hybrids, row spacing reduction and chemical weed management in corn. The experiment was carried out under field conditions, in a randomized complete block design, in a $2 \times 2 \times 5$ factorial scheme, with four replications, with the first factor consisting of corn hybrids (Sprint, too early-maturing and more erect leaves and Penta, early-maturing and more plane leaves), and the second consisting of row spacing $(0.45$ and $0.90 \mathrm{~m})$ and the third, of the weed control treatments: 1 .atrazine + simazine $\left(1.500+1.500\right.$ g.a.i. ha $\left.{ }^{-1}\right)$ at early post-emergence; 2.atrazine + simazine $\left(1.500+1.500 \mathrm{~g}\right.$ a.i. ha $\left.\mathrm{h}^{-1}\right)$, in early post-emergence, complemented by nicosulfuron+atrazine $\left(20+750 \mathrm{~g}\right.$ a.i. $\left.\mathrm{ha}^{-1}\right)$, at late post-emergence; 3.atrazine+simazine $\left(750+750 \mathrm{~g}\right.$ a.i. $\left.\mathrm{ha}^{-1}\right)$, at early post-emergence; 4.control with weeding; 5 . only nicosulfuron+ atrazine $\left(20+750 \mathrm{~g}\right.$ a.i. $\left.\mathrm{ha}^{-1}\right)$, in late post-emergence. The $45 \mathrm{~cm}$ spacing favored weeds in the row while in the $90 \mathrm{~cm}$ spacing, the greatest weed infestations occurred in the interrows. Complementary applications of atrazine + nicosulfuron were needed to control weeds in the Spring hybrid and conventional row systems, but not to control Penta at the row width used. For the Penta hybrid, reduced spacing decreased corn grain yield, while for the Sprint hybrid, no corn grain yield reduction was observed.
\end{abstract}

Keywords: plant arrangement, cultural weed control, integrated weed management.

1 Recebido para publicação em 27.4.2007 e na forma revisada em 15.1.2008.

2 Eng ${ }^{-}-A_{g r}{ }^{\circ}$, Dr., Professor do Curso de Agronomia da UTFPR, Campus Pato Branco. Via do Conhecimento, km 01, Caixa Postal

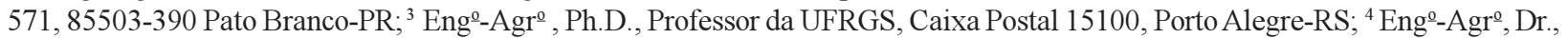
Professor da UFSM, Santa Maria-RS; ${ }^{5}$ Eng $^{-}-$Agr $^{\mathrm{o}}$, Cooperativa Coopavel, Realeza-PR; ${ }^{6}$ Eng$^{\mathrm{o}}-\mathrm{Agr}^{\mathrm{o}}$, Cooperativa Camisc, Mariópolis-

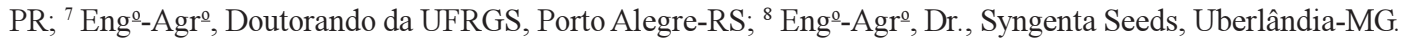




\section{INTRODUÇÃO}

O controle químico é o método mais empregado no manejo de plantas daninhas na cultura de milho. No entanto, estratégias de manejo centradas em um único método selecionam plantas daninhas tolerantes ou resistentes a esse método (Fleck, 2000). O manejo integrado de plantas daninhas (MIPD) é considerado a principal ferramenta para reduzir o impacto ambiental dos herbicidas. O MIPD baseia-se na integração de métodos de controle, tornando os sistemas de cultivo desfavoráveis às plantas daninhas, minimizando seus efeitos. Entre as técnicas utilizadas no MIPD, destacam-se o emprego de culturas intercalares (Haan et al., 1994), e cultivares mais competitivos (Ford \& Pleasant, 1994) a aplicação de herbicidas em faixas (Pleasant et al., 1994), a irrigação (Vangessel et al., 1995), o aumento da densidade de plantas (Merotto Jr. et al., 1997) e a redução de espaçamentos entre linhas (Shrestha et al., 2001).

Populações elevadas e espaçamentos reduzidos entre linhas de semeadura na cultura do milho são estratégias de manejo que interferem no ambiente das plantas cultivadas, modificando suas características morfofisiológicas. Essas estratégias também podem modificar as relações de interferência entre plantas cultivadas e plantas daninhas (Carvalho \& Durigan, 1999). As relações de interferência ainda são influenciadas por características do sistema de manejo, como cultivar e herbicidas utilizados.

A interceptação de radiação pela cultura do milho pode ser aumentada pelo uso de espaçamentos mais estreitos entre linhas e densidades mais elevadas (Begna et al., 2001). Isso resulta em redução da disponibilidade de radiação solar para a porção inferior do dossel. Híbridos com arquitetura moderna, ou seja, com menor estatura, menor número de folhas e folhas mais eretas, possibilitam maior penetração de radiação para a porção inferior do dossel, reduzindo a competição intra-específica mesmo com utilização de densidades mais elevadas (Almeida et al., 2000; Argenta et al., 2001).

A redução do espaçamento entre linhas de milho contribui para o controle de plantas daninhas que se estabeleceram tardiamente na área cultivada (Shrestha et al., 2001). Knezevic et al. (2003) observaram que a redução do espaçamento entre linhas de soja de 76 para 38 ou $19 \mathrm{~cm}$ possibilitou o retardamento do período de controle de plantas daninhas. No entanto, Johnson \& Hoverstad (2002) observaram que a redução dos espaçamentos entre linhas de milho não reduziu a infestação nem o crescimento de espécies precoces ou tardias de plantas daninhas, bem como não influenciou a época de controle destas.

Alguns trabalhos evidenciam que espaçamentos reduzidos, até determinado limite, mantendo-se as mesmas populações de plantas por unidade de área, propiciam maiores rendimentos de grãos (Argenta et al., 2001; Shrestha et al., 2001; Johnson \& Hoverstad, 2002; Strieder, 2006). Isso ocorre pela distribuição mais uniforme de plantas cultivadas, que resulta em maior interceptação de radiação, melhor aproveitamento da água e dos nutrientes e menor evaporação de água.

Um problema do uso de espaçamentos reduzidos é que, algumas vezes, a infestação de plantas daninhas na linha de semeadura é maior do que nas entrelinhas (Bianchi, 1998; Vidal \& Trezzi, 2004), o que pode representar uma maior infestação geral, em relação aos espaçamentos convencionais das entrelinhas. Outra limitação enfrentada pelos agricultores é que os equipamentos tratorizados para controle de plantas daninhas não permitem a execução de operações de controle em estádios de desenvolvimento tardios do milho, sem que aumentem significativamente os danos causados por amassamento de plantas.

Há tendência de que híbridos de milho modernos apresentem maior eficiência no uso de radiação, pois possuem menor número de folhas, folhas mais eretas e menor área foliar, o que minimiza a competição entre plantas, reduzindo a relação entre radiação vermelho extremo e vermelho $(\mathrm{Ve} / \mathrm{V})$ e as taxas de esterilidade da inflorescência feminina (Sangoi et al., 2003). Em experimento conduzido na região de Pato Branco (PR), o híbrido com folhas mais largas, planófilas e com ciclo maior foi mais eficiente em reduzir a massa seca de plantas daninhas, no espaçamento de $0,9 \mathrm{~m}$, enquanto o híbrido com folhas mais eretas, estreitas e ciclo mais curto foi mais eficiente em reduzir a matéria seca de plantas 
daninhas no espaçamento de 0,45 (Nunes et al., 2004).

Comparando seis híbridos com variações na estatura e no ângulo foliar e utilizando quatro doses da associação de alachlor+atrazine em pré-emergência $(0 ; 0,73+0,5 ; 1,45+1,0$; e 2,2 + 1,5 g i.a. ha-1), Roggenkamp et al. (2000) concluíram que os híbridos de milho influenciaram menos a infestação de plantas daninhas do que as doses de herbicidas. Estas são recomendadas em quantidades que assegurem amplo espectro de ação, sob diversos niveis de suscetibilidade e sob condições ambientais que são, na maioria das vezes, diferentes daquelas consideradas ideais para uma ótima ação do herbicida (Vidal, 2002). É importante observar que a redução da dose do herbicida é dependente de vários fatores, como o ingrediente ativo utilizado, já que é provável que herbicidas com eficácia de controle mais elevada para uma determinada espécie daninha permitam reduções de doses mais significativas do que aqueles com menor eficácia. A redução de dose depende também da espécie daninha alvo e seu estádio de desenvolvimento, do método de aplicação (Fleck, 1994) e das condições de ambiente no momento da aplicação (Fundação ABC, 1996). As condições de temperatura, umidade relativa do ar e velocidade dos ventos são menos favoráveis à aplicação de herbicida em periodos entre 10 e 16 horas (Fundação ABC, 1996). Embora não se recomende aplicar herbicidas em situações desfavoráveis, problemas como falta de planejamento ou condições meteorológicas inadequadas são responsáveis por aplicações em períodos do dia desfavoráveis.

Em aplicação de fluazifop-butyl+fomesafen $\left(200+250 \mathrm{~g} \mathrm{ha}^{-1}\right)$ aos 24 dias após a emergência da cultura da soja, a redução de $50 \%$ da dose desses herbicidas $\left(100+125 \mathrm{~g} \mathrm{ha}^{-1}\right)$ foi mais eficiente no controle de plantas daninhas nos maiores espaçamentos $(0,4$ e $0,6 \mathrm{~m}) \mathrm{em}$ relação ao espaçamento reduzido $(0,2 \mathrm{~m})$. Provavelmente esse resultado se deva ao efeito guarda-chuva das plantas de soja nas entrelinhas no espaçamento mais estreito (Pires et al., 2001). Na cultura do milho, no entanto, é possivel que a adoção de espaçamentos reduzidos nas entrelinhas reduza o efeito guardachuva das plantas de milho sobre as plantas daninhas na linha de semeadura, melhorando a eficiência de controle destas. Isso ocorreria porque, nessa condição, as distâncias entre plantas na linha de semeadura são maiores do que nos espaçamentos convencionais.

Neste trabalho, levantou-se a hipótese de que a cobertura mais rápida do solo pela cultura e a menor passagem de radiação para o interior do dossel, resultantes da redução do espaçamento entre linhas de cultivo, poderiam inibir o desenvolvimento das plantas daninhas e, assim, possibilitar a redução de doses de herbicidas para o controle delas. Considerando que características morfofisiológicas de híbridos de milho, como ciclo e ângulo foliar, influenciam a interceptação de radiação solar e, portanto, a infestação de plantas daninhas, é possivel que estas demandem estratégias de controle de plantas daninhas diferenciadas.

Objetivou-se com este trabalho avaliar o efeito da integração de redução de espaçamento entre linhas, características morfofisiológicas de híbridos e estratégias de controle de plantas daninhas em milho.

\section{MATERIAL E MÉTODOS}

O experimento foi realizado na área experimental da Universidade Tecnológica Federal do Paraná, campus Pato Branco, localizada no município de Pato Branco, sendo o solo da área caracterizado como Latossolo Vermelho distrófico. O clima da região é classificado como $\mathrm{Cfb}$, segundo Köppen.

A implantação do experimento ocorreu em início de outubro de 2004, sob delineamento de blocos ao acaso com quatro repetições, em um fatorial $2 \times 2 \times 5$, em que o primeiro fator representou os híbridos de milho de ciclo superprecoce Sprint e Penta - o híbrido Sprint apresenta arquitetura foliar mais ereta em relação ao híbrido Penta; o segundo fator, espaçamentos entre linhas de milho $(0,45$ e $0,90 \mathrm{~m}$ ); e o terceiro, tratamentos de controle de plantas daninhas: 1 . atrazine + simazine $\left(1.500+1.500\right.$ g i.a. ha $\left.{ }^{-1}\right)$ em pós-emergência precoce (pós-precoce); 2. atrazine + simazine $\left(1.500+1.500\right.$ g i.a. ha $\left.{ }^{-1}\right)$, em pós-precoce, complementada por nicosulfuron+atrazine $\left(20+750\right.$ g i.a. ha $\left.{ }^{-1}\right)$, em pós-emergência tardia (pós tardia); 3. atrazine + simazine $\left(750+750\right.$ g i.a. ha $\left.{ }^{-1}\right)$, em pós-precoce; 4. testemunha capinada; e 5. apenas 
nicosulfuron + atrazine $\left(20+750\right.$ g i.a. ha $\left.{ }^{-1}\right)$, em pós-tardia. A cultura do milho foi implantada em sucessão à cultura da aveia-preta (Avena strigosa), a qual foi controlada com duas aplicações seqüenciais de glyphosate $\left(720+720\right.$ g i.a. ha $\left.{ }^{-1}\right)$, respectivamente, realizadas aos 10 e um dia antes da semeadura dos híbridos de milho. A adubação do milho foi feita na linha, no momento da semeadura, com 15,60 e $60 \mathrm{~kg}^{-1}$ de $\mathrm{N}, \mathrm{P}_{2} \mathrm{O}_{5}$ e $\mathrm{K}_{2} \mathrm{O}$, respectivamente. A adubação nitrogenada de cobertura foi parcelada em quantidades iguais de $70 \mathrm{~kg} \mathrm{ha} \mathrm{h}^{-1} \mathrm{de} \mathrm{N}$, sendo a primeira realizada com quatro folhas totalmente expandidas e a segunda com oito (Penta) ou nove folhas totalmente expandidas (Sprint). Realizou-se desbaste quando as plantas de milho estavam com três folhas totalmente expandidas, visando a obtenção de densidade de 65.000 plantas ha ${ }^{-1}$. As dimensões das parcelas utilizadas foram de $16,3 \mathrm{~m}^{2}$ para o espaçamento de $0,45 \mathrm{~m} \mathrm{e}$ $27 \mathrm{~m}^{2}$ para o espaçamento de $0,90 \mathrm{~m}$, para adoção de sete linhas de semeadura por parcela, nos dois espaçamentos.

Os controles populacionais de percevejo barriga-verde (Dichelops spp.) e de lagarta-docartucho (Spodoptera frugiperda) foram obtidos com o inseticida metamidofós (900 g i.a. ha $\left.{ }^{1}\right)$. A aplicação dos herbicidas foi feita com pulverizador costal de precisão, pressurizado com $\mathrm{CO}_{2}$, com pontas 110.02 e vazão de $200 \mathrm{~L} \mathrm{ha}^{-1}$. A aplicação no período pós-precoce foi realizada quando os híbridos estavam com seis a sete folhas e no periodo pós-tardio, com 10 e 9 folhas completamente expandidas, respectivamente, para Sprint e Penta.

Por ocasião da aplicação em pós tardia, que correspondeu a 40 dias após a emergência (DAE) do milho, efetuou-se contagem das plantas daninhas na linha e entre linhas de milho, nas testemunhas sem controle. Nesse momento, também foi avaliado visualmente o controle das espécies daninhas presentes nos tratamentos com aplicação de atrazine + simazine $\left(1.500+1.500\right.$ g i.a. ha $\left.{ }^{-1}\right)$ e atrazine+simazine $\left(750+750\right.$ g i.a. ha $\left.{ }^{-1}\right)$, ambos em pós-precoce. Aos 35 dias após a aplicação dos herbicidas em pós-tardia (75 DAE de milho), coletou-se a parte aérea das espécies daninhas na área interna de um quadro de madeira de 0,5 x 0,5 m, jogado ao acaso na área útil, correspondendo a uma amostra de
$0,2 \mathrm{~m}^{2}$ por parcela, para posterior secagem em estufa a $60^{\circ} \mathrm{C}$, de modo a se obter a matéria seca. Nesse momento, determinou-se também a estatura das plantas de milho, em amostra de dez plantas por parcela.

O rendimento de grãos foi calculado pelo peso de grãos obtido na área útil das parcelas extrapolado para hectare, com posterior padronização da umidade para $13 \%$.

Os dados obtidos foram submetidos à análise de variância pelo teste $\mathrm{F}$ e, em caso de significância dos efeitos simples ou interações, compararam-se as médias dos tratamentos pelo teste de Tukey.

\section{RESULTADOS E DISCUSSÃO}

As principais plantas daninhas encontradas na área experimental foram Euphorbia heterophylla, Avena strigosa e, predominantemente, Brachiaria plantaginea. A análise da variância da infestação total das plantas daninhas nas parcelas sem uso de herbicidas, efetuada logo antes da aplicação de herbicidas em pós-emergência tardia, aos 40 DAE da cultura, não demonstrou efeito simples de híbrido, espaçamento entre linhas de milho, nem da interação entre híbrido e espaçamento, mas demonstrou significância da interação entre espaçamento e localização das plantas daninhas, na linha ou entrelinha.

O espaçamento entre linhas de milho de $0,45 \mathrm{~m}$ implica maior número de linhas de semeadura por área, em comparação ao de $0,90 \mathrm{~m}$, o que resultou em população de plantas daninhas por área $54 \%$ superior nas linhas de semeadura, em relação à população da entrelinha (Tabela 1). Embora não-significativa ( $P>0,05)$, observou-se que, com o aumento do espaçamento de 0,45 para $0,9 \mathrm{~m}$, a infestação na linha reduziu $16 \%$ e, contrariamente, na entrelinha aumentou $28 \%$ (Tabela 1). No espaçamento estreito houve maior revolvimento da palha e do solo com a semeadora e também maior distância entre plantas de milho na linha de semeadura, favorecendo a maior emergência de espécies daninhas fotoblásticas positivas na linha de semeadura, a exemplo do que constataram Bianchi (1998) e Vidal \& Trezzi (2004). No espaçamento de $0,9 \mathrm{~m}$, a decomposição da palhada, aliada ao maior espaço para penetração da radiação solar, favorece a 
elevação da infestação nas entrelinhas. Esse efeito diferencial do espaçamento na infestação da linha e entrelinha foi a causa de se obter a mesma infestação total de plantas daninhas nas áreas sob os dois espaçamentos.

A análise comparativa do controle em pósprecoce, entre atrazine+simazina na dose recomendada $\left(1.500+1.500\right.$ g i.a. ha $\left.{ }^{-1}\right)$ e em meia dose $\left(750+750 \mathrm{~g}\right.$ i.a. ha $\left.{ }^{-1}\right)$, efetuada na mesma época, não demonstrou $(P>0,05)$ efeito simples de híbrido, espaçamento entre linhas, nem da interação entre híbrido e espaçamento, para nenhuma das espécies daninhas avaliadas (Tabela 2).

As plantas de $B$. plantaginea foram mais tolerantes à associação de atrazine+simazina do que $E$. heterophylla e A. strigosa (Tabela 3); dessa forma, a redução dos niveis dos herbicidas pela metade resultou em decréscimo nos niveis de controle dessa espécie, fato não verificado nas demais espécies (Tabela 3). Portanto, até esse momento, a hipótese de que a redução do espaçamento entre linhas permitiria a redução dos níveis de herbicidas utilizados só pôde ser confirmada para $E$. heterophylla $\mathrm{e}$ A. strigosa.

A análise da variância da matéria seca de plantas daninhas, efetuada 35 dias após a aplicação em pós-tardia (75 dias após a emergência do milho), indicou interação tríplice entre os fatores híbrido, espaçamento e métodos de controle.

Para o híbrido Sprint, a matéria seca de plantas daninhas no espaçamento de $0,9 \mathrm{~m}$ foi 3.325 e $966 \%$ superior ao de $0,45 \mathrm{~m}$, respectivamente, nos tratamentos de atrazine + simazina em pós-precoce, na dose recomendada e em meia dose (Tabela 4). Diferenças entre os espaçamentos não foram identificadas para os demais tratamentos herbicidas em que se utilizou Sprint, nem para os tratamentos herbicidas usando Penta. Justifica-se a ocorrência de diferenças entre espaçamentos apenas na aplicação em pós-precoce, porque, em geral, atrazine e simazina apresentam limitado período residual no solo. A capacidade dos herbicidas aplicados em pós-precoce de controlar fluxos mais tardios das espécies $B$. plantaginea, E. heterophylla e A. strigosa é considerada baixa, o que permitiu o desenvolvimento de plantas daninhas onde havia boa
Tabela 1 - Infestação total de plantas daninhas nos tratamentos sem controle, no dia anterior à aplicação de herbicidas em pós-tardia, em função do espaçamento entre linhas e da localização das plantas daninhas, na linha de semeadura ou entrelinha

\begin{tabular}{|l|c|c|c|}
\hline \multirow{2}{*}{$\begin{array}{l}\text { Localização das } \\
\text { plantas daninhas }\end{array}$} & \multicolumn{2}{|c|}{ Espaçamento entre linhas $(\mathrm{m})$} & \multirow{2}{*}{ Média } \\
\cline { 2 - 3 } & 0,45 & 0,90 & \\
\cline { 2 - 3 } & \multicolumn{2}{|c|}{ Plantas daninhas $\mathrm{m}^{-2}$} & \\
\hline Linha & $240 \mathrm{a} * \mathrm{~A}$ & $202 \mathrm{a} \mathrm{A}$ & $221 \mathrm{~A}$ \\
\hline Entrelinha & $110 \mathrm{a} \mathrm{B}$ & $153 \mathrm{a} \mathrm{A}$ & $131 \mathrm{~B}$ \\
\hline Total & $350 \mathrm{n} . \mathrm{s}$. & 355 & \\
\hline
\end{tabular}

* Médias seguidas da mesma letra, minúscula na linha e maiúscula na coluna, não diferem entre si pelo teste de Tukey $(P>0,05)$. n.s. não-significativo pelo teste $F(P>0,05)$

Tabela 2 - Controle (\% em relação à testemunha capinada) de B. plantaginea, E. heterophylla e A. strigosa, no dia anterior à aplicação de herbicidas em pós tardia, em função do híbrido e do espaçamento entre linhas de milho, na média dos tratamentos com aplicação de herbicidas em pós-precoce

\begin{tabular}{|c|c|c|c|c|}
\hline \multirow{2}{*}{ Híbrido } & \multirow{2}{*}{$\begin{array}{c}\text { Espaça } \\
\text { mento }\end{array}$} & \multicolumn{3}{|c|}{ Espécie } \\
\cline { 3 - 5 } & & B.plantaginea & E. heterophylla & A. strigosa \\
\cline { 3 - 5 } & 0,45 & $86 \mathrm{~ns}$ & $92 \mathrm{~ns}$ & $96 \mathrm{~ns}$ \\
\hline \multirow{2}{*}{ Penta } & 0,40 & $73 \mathrm{~ns}$ & $93 \mathrm{~ns}$ & $92 \mathrm{~ns}$ \\
\cline { 2 - 5 } & 0,90 & $78 \mathrm{~ns}$ & $93 \mathrm{~ns}$ & $97 \mathrm{~ns}$ \\
\hline \multirow{2}{*}{ Sprint } & 0,45 & $76 \mathrm{~ns}$ & $97 \mathrm{~ns}$ & $99 \mathrm{~ns}$ \\
\cline { 2 - 5 } & 0,90 & &
\end{tabular}

ns Não-significativo pelo teste $\mathrm{F}(\mathrm{P}>0,05)$.

Tabela 3 - Controle (\% em relação à testemunha capinada) de B. plantaginea, E. heterophylla e $A$. strigosa, no dia anterior à aplicação de herbicidas em pós-tardia, em função da dose de atrazina + simazina em pós-emergência precoce, na média dos híbridos e espaçamentos entre linhas

\begin{tabular}{|l|c|c|}
\hline \multirow{2}{*}{ Espécie } & $\begin{array}{c}\text { Atrazina }+ \text { simazina } \\
\left(\begin{array}{c}1.500+1.500 \mathrm{~g} \mathrm{i.a.} \mathrm{ha} \\
+ \text { óleo mineral }\end{array}\right.\end{array}$ & $\begin{array}{c}\text { Atrazina + simazina } \\
\left(750+750 \mathrm{~g} \mathrm{i.a.} \mathrm{ha}{ }^{-1}\right) \\
+ \text { óleo mineral }\end{array}$ \\
\cline { 2 - 3 } & Controle $(\%$ em relação à testemunha) \\
\hline B. plantaginea & $87 \mathrm{a}^{*}$ & $70 \mathrm{~b}$ \\
\hline E. heterophylla & $95 \mathrm{n} . \mathrm{s}$. & 90 \\
\hline A. strigosa & $98 \mathrm{n} . \mathrm{s}$. & 94 \\
\hline
\end{tabular}

* Médias seguidas da mesma letra na linha não diferem entre si pelo teste $\mathrm{F}(\mathrm{P}>0,05)$.

disponibilidade de recursos, notadamente no maior espaçamento e com o híbrido Sprint. Em espaçamentos reduzidos, evidenciou-se maior habilidade da cultura do milho em ocupar mais precocemente o espaço aéreo com seu dossel, o que beneficia sobretudo os cultivares com folhas mais eretas (Silva et al., 2006). Com Sprint, em espaçamento entre linhas de 0,9 m, os herbicidas atrazine+nicosulfuron em pós-tardia e atrazine + simazina em pós-precoce, 
Tabela 4 - Matéria seca total de plantas daninhas em resposta a distintos métodos de controle, híbridos e espaçamentos entre linhas

\begin{tabular}{|c|c|c|c|c|c|c|}
\hline \multirow[b]{2}{*}{ Híbrido } & \multirow[b]{2}{*}{ Esp. } & \multicolumn{5}{|c|}{ Método de controle de plantas daninhas } \\
\hline & & $\begin{array}{l}\text { Testemunha } \\
\text { capinada }\end{array}$ & $\begin{array}{l}\text { Atrazine }+ \text { simazine } \\
+ \text { dose cheia PP }\end{array}$ & $\begin{array}{c}\text { Atrazine }+ \text { simazine } \\
\mathrm{PP}+\text { atrazine }+ \\
\text { nicosulfuron PT }\end{array}$ & $\begin{array}{c}\text { Atrazine }+ \text { simazine } \\
1 / 2 \text { dose PP }\end{array}$ & $\begin{array}{c}\text { Atrazine }+ \\
\text { nicosulfuron PT }\end{array}$ \\
\hline \multirow{2}{*}{ Penta } & 0,45 & $\mathrm{~A}^{\mathrm{l} 0 \mathrm{aA}}$ & A $11,1 \mathrm{a}^{2} \mathrm{~A}$ & A $2,66 \mathrm{aA}^{3}$ & A $26,8 \mathrm{aA}$ & A 16,0 aA \\
\hline & 0,90 & $\mathrm{~A} 0 \mathrm{aA}$ & $\mathrm{B} 11,9 \mathrm{aA}$ & A 7,15 aA & $\mathrm{B} 15,8 \mathrm{aA}$ & A 24,9 aA \\
\hline \multirow{2}{*}{ Sprint } & 0,45 & $\mathrm{~A} 0 \mathrm{aA}$ & A $1,6 \mathrm{bA}$ & A 0,68 aA & A $10,9 \mathrm{bA}$ & $\mathrm{A} 8,8 \mathrm{aA}$ \\
\hline & 0,90 & $\mathrm{~A} 0 \mathrm{aC}$ & A $54,8 \mathrm{aAb}$ & A $6,05 \mathrm{aC}$ & A 116,2 aA & A $12,0 \mathrm{aBCC}$ \\
\hline
\end{tabular}

$\mathrm{PP}=$ pós-emergência precoce, 22 dias após a emergência do milho.

PT = pós-emergência tardia, 40 dias após a emergência do milho

${ }^{1}$ Mesmas letras maiúsculas antecedendo as médias indicam ausência de diferença significativa, correspondendo à comparação entre híbridos em cada um dos espaçamentos e em cada método de controle de plantas daninhas, pelo teste de Tukey $(\mathrm{P}>0,05)$.

${ }^{2}$ Mesmas letras minúsculas sucedendo as médias indicam ausência de diferença significativa, correspondendo à comparação entre espaçamentos em cada um dos métodos de controle e em cada um dos híbridos, pelo teste de Tukey $(\mathrm{P}>0,05)$.

${ }^{3}$ Mesmas letras maiúsculas sucedendo médias indicam ausência de diferença significativa, correspondendo à comparação entre métodos de controle de plantas daninhas, para cada híbrido e espaçamento, pelo teste de Tukey $(\mathrm{P}>0,05)$.

complementado com o uso de atrazine+nicosulfuron em pós-tardia, controlaram as espécies daninhas, refletindo em matérias secas mais baixas do que as apresentadas apenas com herbicidas aspergidos em pós-emergência precoce (Tabela 4).

O uso de Sprint em espaçamento de 0,45 m e de Penta em ambos os espaçamentos não resultou em diferenças significativas de matéria seca entre os métodos de controle químico de plantas daninhas, demonstrando a possibilidade da redução da dosagem ou mesmo a abolição de aplicações complementares em cultivos conduzidos nessas condições (Tabela 4). É importante observar que a redução da dose de herbicidas não pode ser feita sem antes avaliar uma série de fatores, entre os quais o produto utilizado e seu método de aplicação, a espécie daninha alvo e o seu estádio de desenvolvimento (Fleck, 1994) e condições de ambiente no momento da aplicação (Fundação ABC, 1996). A decisão de reduzir dose ou de utilizar ou não aplicação complementar não deve ser baseada apenas na eficiência de controle, mas deve considerar, também, o rendimento de grãos e as reinfestações de plantas daninhas nas safras seguintes.

A diferença de matéria seca de plantas daninhas entre espaçamentos provavelmente manifestou-se em Sprint, e não em Penta, em função da arquitetura folhar mais ereta do primeiro e do ciclo mais precoce, o que proporciona maior passagem de radiação solar às entrelinhas da cultura do milho, permitindo, dessa forma, maior desenvolvimento das plantas daninhas nas entrelinhas em estádios mais tardios. Demonstra-se, dessa forma, que Sprint não facilita o controle de plantas daninhas quando conduzido no espaçamento de $0,90 \mathrm{~m}$, principalmente quando utilizadas dosagens reduzidas ou sem aplicações complementares.

Esses dados estão de acordo com os obtidos em Pato Branco (PR), em que o híbrido com folhas mais planas e com ciclo maior foi mais eficiente em reduzir a matéria seca de plantas daninhas no espaçamento de $0,9 \mathrm{~m}$, enquanto o híbrido com folhas mais eretas e ciclo mais curto foi mais eficiente em reduzir a matéria seca de plantas daninhas no espaçamento de 0,45 do que no de 0,9 m (Nunes et al., 2004). Também são respaldados pelo experimento conduzido em Canoinhas (SC), em que a avaliação da matéria seca, aos 80 dias, em dois cultivares com características morfológicas diferentes, apontou vantagem do híbrido sobre o cultivar de polinização aberta em espaçamento reduzido $(0,4 \mathrm{~m})$, ao passo que nos espaçamentos largos $(0,8$ e 1,0 m) houve maior capacidade de supressão do cultivar de polinização aberta, com maior estatura e maior número de folhas (Balbinot Jr. \& Fleck, 2005).

A análise da variância do rendimento de grãos indicou ser significativo o efeito da interação entre híbrido e espaçamento e entre híbrido e métodos de controle de plantas daninhas. A redução do espaçamento entre linhas 
não contribuiu para elevar o rendimento de grãos. Para o híbrido Penta, a diminuição do espaçamento reduziu o rendimento de grãos (Tabela 5). Já para Sprint não houve diferença no uso de espaçamento entre linhas de $0,9 \mathrm{~m}$ e de $0,45 \mathrm{~m}$. A redução de rendimento do híbrido Penta com o uso de espaçamento reduzido não era esperada, pois, em geral, ocorre redução da competição interespecífica em espaçamentos estreitos. No entanto, pode ocorrer maior competição por radiação entre plantas de linhas diferentes, especialmente em híbridos com folhas mais planófilas, como é o caso de Penta. O híbrido Sprint apresentou maior redução de estatura do que Penta sob espaçamento entre linhas reduzido $(0,45 \mathrm{~m})$ (Tabela 6), fato que provavelmente contribui para maior competição por radiação entre linhas em Penta.

Os estudos de redução do espaçamento entre linhas sobre o rendimento de grãos de milho apresentam resultados bastante heterogêneos. Enquanto alguns resultados indicam aumentos expressivos de rendimento de grãos com a redução do espaçamento entre linhas (Shrestha et al., 2001; Johnson \& Hoverstad, 2002; Balbinot Jr. \& Fleck, 2005; Strieder, 2006), outros não indicam esse incremento

Tabela 5 - Rendimento de grãos de milho em função do híbrido e do espaçamento entre linhas

\begin{tabular}{|c|c|c|}
\hline \multirow{2}{*}{ Híbrido } & \multicolumn{2}{|c|}{ Espaçamento $(\mathrm{m})$} \\
\cline { 2 - 3 } & \multicolumn{2}{|c|}{ Rendimento de grãos $\left(\mathrm{kg} \mathrm{ha}^{-1}\right)$} \\
\cline { 2 - 3 } & $10099 \mathrm{~b} \mathrm{~A}$ & $11010 \mathrm{a} \mathrm{A}$ \\
\hline Penta & $9726 \mathrm{a} \mathrm{A}$ & $10135 \mathrm{a} \mathrm{B}$ \\
\hline Sprint & & 0.9 \\
\hline
\end{tabular}

${ }^{1}$ Médias acompanhadas pelas mesmas letras, minúsculas na linha e maiúsculas na coluna, não diferem estatisticamente pelo teste de Tukey $(P>0,15)$.

Tabela 6 - Estatura de plantas de milho em função do híbrido e do espaçamento entre linhas

\begin{tabular}{|c|c|c|}
\hline \multirow{2}{*}{ Híbrido } & \multicolumn{2}{|c|}{ Espaçamento (m) } \\
\cline { 2 - 3 } & 0,45 & 0,9 \\
\cline { 2 - 3 } & \multicolumn{2}{|c|}{ Estatura $(\mathrm{cm})$} \\
\hline Penta & $214,4 \mathrm{a} \mathrm{A}$ & $211,6 \mathrm{a} \mathrm{A}$ \\
\hline Sprint & $208,8 \mathrm{~b} \mathrm{~B}$ & $215,5 \mathrm{a} \mathrm{A}$ \\
\hline
\end{tabular}

${ }^{1}$ Médias acompanhadas pelas mesmas letras, minúsculas na linha e maiúsculas na coluna, não diferem estatisticamente pelo teste de Tukey $(P>0,15)$.
(Teasdale, 1995; Nunes et al., 2004). Fatores como híbrido e população de plantas (Argenta et al., 2001) e época de semeadura (Sangoi et al., 2001) podem contribuir para a variabilidade de resultados. Superioridade no rendimento de grãos devido à redução de espaçamento em milho apenas na densidade de 50.000 plantas, e não na de 65.000 plantas ha- $^{-1}$, a mesma utilizada no presente experimento, foi detectada por Argenta et al. (2001). Segundo esses autores, enquanto a competição intraespecífica é reduzida nos espaçamentos menores, densidades mais elevadas poderiam reduzir a passagem de radiação para o interior do dossel.

Para o híbrido Sprint, os rendimentos de grãos obtidos com as diferentes estratégias químicas de manejo de plantas daninhas não diferiram entre si nem com a testemunha capinada (Tabela 7). Isso pode indicar que a competição exercida entre as plantas daninhas com Sprint, em fases iniciais, antes da aplicação da associação de herbicidas em pós-tardia, bem como aquela exercida após o término do efeito residual de atrazine+simazina no solo, foi pouco expressiva.

Para Penta, embora os tratamentos com métodos de controle químico não tenham diferido da testemunha capinada, os tratamentos que incluíram a aplicação de herbicidas em pós-tardia, aos 40 dias após a emergência da cultura, fizeram parte do grupo em que se obteve o rendimento de grãos de milho mais elevado (Tabela 7). Como a superioridade do rendimento de grãos de Penta em relação a Sprint, nos tratamentos com aplicação de herbicidas em pós-tardia, não pode ser explicada pelas diferenças de infestação de plantas daninhas entre os híbridos nesses tratamentos (Tabelas 4 e 7), isso indica menor tolerância de Penta às infestações tardias em relação a Sprint.

Considerando os resultados obtidos, conclui-se que híbridos com arquitetura foliar mais ereta, em espaçamentos largos, podem apresentar maiores infestações de plantas daninhas em relação a híbridos de folhas mais planas, podendo necessitar de aplicações complementares de herbicidas. Portanto, a adoção de espaçamentos reduzidos é uma estratégia de grande importância no controle sustentável de plantas daninhas, sobretudo para híbridos 
Tabela 7 - Rendimento de grãos de milho em função do híbrido e do método de controle de plantas daninhas

\begin{tabular}{|c|c|c|c|c|c|}
\hline \multirow{3}{*}{ Híbrido } & \multicolumn{5}{|c|}{ Método de controle de planta daninha } \\
\hline & $\begin{array}{c}\text { Testemunha } \\
\text { capinada }\end{array}$ & $\begin{array}{c}\text { Atrazine }+ \\
\text { simazine PP }\end{array}$ & $\begin{array}{c}\text { Atrazine }+ \text { simazine } \\
\mathrm{PP}+\text { atrazine }+ \\
\text { nicosulfuron PT }\end{array}$ & $\begin{array}{c}\text { Atrazine }+ \\
\text { simazine } 1 / 2 \text { dose } \\
\text { PP }\end{array}$ & $\begin{array}{c}\text { Atrazine }+ \\
\text { nicosulfuron PT }\end{array}$ \\
\hline & \multicolumn{5}{|c|}{ - } \\
\hline Penta & $10240 \mathrm{ab} \mathrm{A}^{1}$ & $9927 \mathrm{~b} \mathrm{~A}$ & $11010 \mathrm{ab} A$ & $10472 \mathrm{ab} A$ & 11126 a A \\
\hline Sprint & 10377 a A & 9765 a A & 10047 a B & $9707 \mathrm{aA}$ & 9756 a B \\
\hline
\end{tabular}

${ }^{1}$ Médias acompanhadas pelas mesmas letras, minúscula na linha e maiúscula na coluna, não diferem estatisticamente pelo teste de Tukey $(\mathrm{P}>0,06)$.

com arquitetura mais ereta. A redução na dosagem de herbicidas torna-se possivel desde que sejam adotadas técnicas complementares no controle de plantas daninhas, como, por exemplo, redução no espaçamento ou híbridos de arquitetura foliar mais plana, que complementem a ação desses produtos. No entanto, essa prática não pode ser utilizada indiscriminadamente e poderá aumentar o número de propágulos produzidos e as infestações futuras de plantas daninhas.

\section{LITERATURA CITADA}

ALMEIDA, M. L. et al. Incremento na densidade de plantas: uma alternativa para aumentar o rendimento de grãos de milho em regiões de curta estação estival de crescimento. $\mathbf{C i}$. Rural, v. 30, n. 1, p. 23-29, 2000.

ARGENTA, G. et al. Resposta de híbridos simples de milho à redução do espaçamento entre linhas. Pesq. Agropec.

Bras., v. 36, n. 1, p. 71-78, 2001

BALBINOT JR.; FLECK, N. G. Manejo de plantas daninhas na cultura de milho em função do arranjo espacial de plantas e características dos genótipos. Ci. Rural, v. 34, n. 6, p. $245-252,2004$

BEGNA, S. H. et al. Weed biomass production response to plant spacing and corn (Zea mays) hybrids differing in canopy architecture. Weed Technol., v. 15, n. 4, p. 647-653 2001.

BIANCHI, M. Manejo integrado de plantas daninhas. In: AUTOR. A cultura do milho no plantio direto. Cruz Alta: Fundacep Fecotrigo, 1998. p. 128-143

CARVALHO, F. T.; DURIGAN, J. C. Integração de práticas culturais e redução da dose do bentazon na cultura da soja. IEfeitos sobre o crescimento da cultura. Planta Daninha, v. 17, n. 1, p. 197-206, 1999.
FLECK, N. G. Doses reduzidas de herbicidas de pósemergência para controle de papuã em soja. Planta Daninha, v. 12, n. 1, p. 21-28, 1994

FLECK, N. G. Controle de plantas daninhas na cultura do arroz irrigado através da aplicação de herbicidas com ação seletiva. Porto Alegre: Edição do Autor, 2000. 32 p.

FORD, G. T.; PLEASANT, J. M. T. Competitive abilities of six corn (Zea mays) hybrids with four weed control practices. Weed Technol., v. 8, p. 124-128, 1994.

FUNDAÇÃO ABC. Conquiste o futuro com a tecnologia presente: tecnologia de aplicação de defensivo. Ponta Grossa: 1996. $36 \mathrm{p}$

HAAN, R. L. et al. Simulation of spring-seeded smother plants for weed control in corn (Zea mays). Weed Sci., v. 42 , p. $35-43,1994$

JOHNSON, G. A.; HOVERSTAD, T. R. Effect of row spacing and herbicide application timing on weed control and grain yield in corn (Zea mays). Weed Technol., v. 16, n. 3, p. $548-553,2002$.

KNEZEVIC, S. Z. et al. Row spacing influences the critical timing for weed removal in soybean (Glycine max). Weed Technol., v. 17, n. 4, p. 666-673, 2003.

MEROTTO JR., A. et al. Aumento da população de plantas e uso de herbicidas no controle de plantas daninhas em milho. Planta Daninha, v. 15, n. 2, p. 141-151, 1997.

NUNES, A. L. et al. Potencial de supressão de plantas daninhas na cultura do milho (Zea mays) com uso de diferentes híbridos, espaçamentos entre linhas e níveis de herbicidas em pós-emergência. B. Inf. SBCPD, v. 10, p. 233 , 2004.

PIRES, J. L. F.et al. Redução da dose do herbicida aplicado em pós-emergência associada a espaçamento reduzido da cultura de soja para controle de Brachiaria plantaginea. Planta Daninha, v. 19, n. 3, p. 337-343, 2001 
PLEASANT, J. M. T.et al. Integrating mechanical and chemical weed management in corn (Zea mays). Weed Technol., v. 8, n. 2, p. 217-223, 1994

ROGGENKAMP, G. J. et al. Velvetleaf (Abutilon theophrasti) and green foxtail (Setaria viridis) response to corn (Zea mays) hybrid. Weed Technol., v. 14, n. 2, p. 304$311,2000$.

SANGOI, L. et al. Influence of row spacing reduction on maize grain yield in regions with a short summer. Pesq. Agropec. Bras., v. 36, n. 6, p. 861-869, 2001.

SANGOI, L. et al. Bases morfo-fisiológicas para aumentar a tolerância de cultivares de milho a altas densidades de plantas. In: REUNIÃO TÉCNICA CATARINENSE DE MILHO E FEIJÃO, 4., 2003, Lages. Resumos expandidos... Lages: CAV-UDESC, 2003. p. 19-24.

SILVA, P. R. F. et al. Arranjo de plantas e sua importância na definição da produtividade em milho. Porto Alegre: Universidade Federal do Rio Grande do Sul; Lages: UDESC; Uberlândia: Syngenta Seeds, Evangraf, 2006. 64 p.
SHRESTA, A. et al. An integrated weed management strategy for glufosinate-resistant corn (Zea mays). Weed Technol., v. 15, n. 4, p. 517-522, 2001.

STRIEDER, M. L. Resposta do milho à redução do espaçamento entre linhas em diferentes sistemas de manejo. 2006. 94 f. Dissertação (Mestrado em Fitotecnia) Universidade Federal do Rio Grande do Sul, Porto Alegre, 2006.

TEASDALE, J. R. Influence of narrow row/high population corn on weed control and light transmittance. Weed Technol., v. 9, n. 1, p. 113-118, 1995.

VANGESSEL, M. J. et al. Influence of weed density and distribuition on corn (Zea mays) yield. Weed Sci., v. 43, n. 2, p. 215-218, 1995.

VIDAL, R. A.; TREZZI, M. M. Potencial de utilização de cobertura vegetal de sorgo e milheto na supressão de plantas daninhas na condição de campo I- Plantas em desenvolvimento vegetativo. Planta Daninha, v. 22, n. 2 , p. $217-223,2004$

VIDAL, R. A. Ação dos herbicidas. Absorção, translocação e metabolização. Porto Alegre: Ribas Vidal, 2002. v. 1. 89 p. 